\title{
PRACTICAL EDUCATION OF ADULTS WITH INTELLECTUAL DISABILITIES USING A WEB COURSE
}

\author{
Petr Benda, Jan Pavlík, Jan Masner \\ Czech University of Life Sciences Prague, Czech Republic \\ E-mail: bendap@pef.czu.cz, pavlikjan@pef.czu.cz, masner@pef.czu.cz
}

\begin{abstract}
Education of adults with intellectual disabilities in labor activities can help them to successfully and repeatedly carry out their work tasks and significantly help their self-realization. The problem is that the need for frequent repetition of already learned skills requires the constant presence of a teacher or caregiver since such a worker is not able to work independently. This situation increases the cost of employing people with disabilities. The aim is to find a way to reduce the necessary number of caregivers needed in this kind of activity and enable greater self-sufficiency of workers. The presented research intended to verify whether a web course could be an effective educational tool for people with intellectual disabilities. During the research, a group of ten participants with intellectual disabilities was educated to acquire basic skills in horticulture. The first teaching was realized through practical demonstrations at the workplace in the university production garden by professional gardeners. After these demonstrations skills of all participants were verified and so the basic level for further verification and comparison of knowledge was set. Subsequently, using three approaches of repeating the already learned practical curriculum (verbal repetition, no repetition, and repetition using the web course) and different time intervals, the level of knowledge of each participant was verified. Statistical methods were used to compare the results of different repetition approaches. Research results demonstrated that a web course, with specific content that consists of video or animation, combined with the use of pictograms for confident navigation, can be used by people with intellectual disabilities with good results. At the same time, in addition to practical teaching, this was the second best-rated approach of repeating knowledge. Using a web course, participants achieved similar work results as they did in practical teaching.

Keywords: adult education, intellectual disabilities, professional education, web course.
\end{abstract}

\section{Introduction}

Education is identified as a fundamental human right and crucial to the overall development of an individual. It transforms lives, empowers the individual and yields greater choices and opportunities. Education can break the cycle of disadvantaged and persons with intellectual disabilities can work as hard as anyone else. In the Factsheet of United Nations Department of Public Information (2007), there is information about the global problem with the employment of persons with disabilities, wherein developing countries, between $80 \%$ and $90 \%$ of people with disabilities are unemployed, while in industrialized countries it is between $50 \%$ and $70 \%$. Specifically, in the European Union, there are around 40 million disabled people and $43 \%$ to $54 \%$ have been working-age in 1998. People with disabilities are two to three times more likely to be unemployed than others. Evans (2007) has found that people with disabilities represent one-fifth of the working-age population in the United Kingdom, however, they are more likely to be unemployed and lack skills than the rest of the population. Evans (2007) has also found it necessary to take major steps to improve the skills of people with disabilities because improving the employment rate of disabled people would boost the UK economy by 
PROBLEMS

OF EDUCATION IN THE $21^{\text {st }}$ CENTURY Vol. 77 , No. 4, 2019

464
$£ 13$ billion, which is equivalent to six months economic growth. In terms of world-leading levels, improving the skills of disabled people by 2020 would give a boost equivalent to 18 extra months of growth over 30 years, so about $£ 35$ billion.

Other research (Kober \& Eggleton, 2005; Kraemer, McIntyre, Blacher, \& Taylor, 2003) also confirmed that employment improves the quality of life in the population of people with disabilities as well as in the general population. For more, employment can help to realize social relations and to provide a good opportunity for people with intellectual disabilities to meet others who are not associated with intellectual disability services (Forrester-Jones, Jones, Heason, \& Di Terlizzi, 2004). Another benefit of employing persons with intellectual disabilities has mentioned Clarke and Clarke (2003) who state that there are often improvements in cognitive abilities, particularly when individuals are moved from very impoverished or adverse environments. Eggleton, Robertson, Ryan, \& Kober (1999) have indicated that the quality of life of employed persons with disabilities is significantly higher than in the situation of unemployed people.

Intellectual disability is defined by Schalock et al. (2010) as a developmental disability characterized by limitations in intellectual functioning and adaptive behavior, resulting in the need for extraordinary support for a person to participate in activities involved with typical human functioning. At present, work-based education and employment of adults with an intellectual disability are realized mainly by two models: Sheltered and Supported (Integrated) employment (Kregel \& Dean, 2002). Although sheltered employment is preferred and supported by many countries, the application of this program may have a number of disadvantages and higher costs. Murphy and Rogan (1995) have presented in their research that the long-term impact of sheltered employment on the productivity and community integration of individuals with disabilities is very small and only very few individuals are able to progress into competitive employment. Kregel and Dean (2002) have found that integrated employment options cost less than sheltered workshops, activity centers or other day support options for individuals with disabilities. Local employment programs can serve more individuals for the same amount of money and achieve better outcomes if they adopt an integrated employment approach. Farris and Stancliffe (2001) supported this conclusion by their research in which they have presented that the co-worker training model in supported employment may provide a viable, cost-effective alternative to the traditional sheltered place and train model. It is also necessary to mention Eggleton et al. (1999) conclusions in which they have expressed that difference in the quality of life of those individuals who had previously attended a sheltered workshop and those who remained unemployed is not statistically significant. Many types of research and case studies in recent years (Adam \& Tatnall, 2008; Quinn, 1996; Perera, Wijerathne, Wijesooriya, Dharmarathne, \& Weerasinghe, 2012; Pillay, 2000) have also confirmed positive use of technology and ICT equipment in teaching students with disabilities and special needs.

\section{Problem of Research}

In general, people with intellectual disabilities need re-practice to handle the task because they have difficulty with memory, motivation, and attention (Turnbull, Turnbull, Wehmeyer, \& Shogren, 2012). Participants of the presented research demonstrated quick forgetting of previously learned activities during the working process. Ellis (1970) and Swanson (1989) reached similar conclusions. The need for frequent repetition of previously learned skills requires constant presence of the teacher, assistant or a caregiver and most participants are not able to work independently. This is not a good practice in many areas including horticulture, on which this research is focusing. The reason is the need for diversification of work. Especially in smaller gardening shops, it is appropriate for employees to work on different tasks and possibly independently. If it were shown that employees with mental disabilities are capable 
to use the web courses to repeat working activities, it would be possible to let them work more independently at various activities. The teacher or caregiver would then become more of a supervisor.

According to the motto of the National Association of Social Workers (NASW), "Helping people help themselves," (Liberman \& Kopelowicz, 2002), it is appropriate to explore whether a web course could be an effective educational tool for people with intellectual disabilities focusing on repetition of knowledge, that these students have previously obtained during practical teaching.

The aim of the research was to find out if the work results of employees with disabilities, who work in the workplace with the help of an assistant or a caregiver differ from those who use as assistance only the web course. The course was focused on the repetition of activities that students have previously learned during the practical teaching. The research was situated in the Production Garden of Czech University of Life Sciences Prague (CULS) to allow participants with intellectual disabilities to work together with regular employees.

Evaluation of each employee was performed gradually in six steps by so-called Validated Observations (Figure 1). The first observation was made at the end of the first week after the original practical teaching. Further Validated observations were made at different weekly intervals. All research was conducted from May to September 2017. A web course and its content were also been produced within the first three weeks of research.

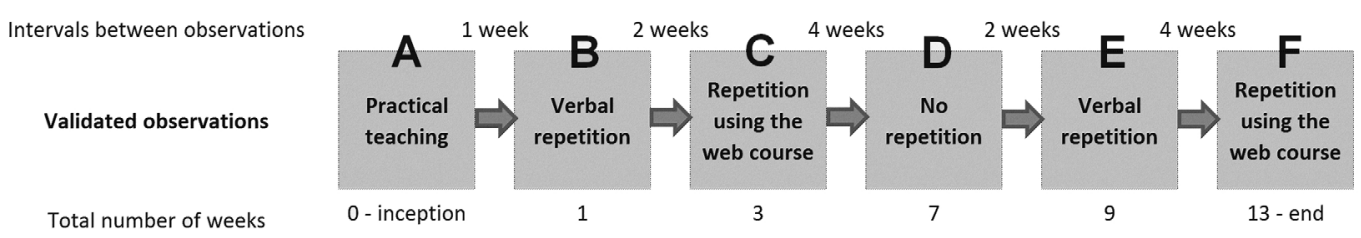

Figure 1. Validated observations schedule.

Although the main aim was to clarify the use of the web course as partial goals, it was to find out how the use of the web course differs from verbal repetition of knowledge by caregivers and the situation when the participant is unable to use any help, so to use no repetition of knowledge thus to use only previously acquired knowledge. All objectives related to comparing Validated observations can be defined as research questions. Two other research objectives were the identification of the content type of the developed web source and selection of appropriate navigation elements.

\section{Research Questions}

RQ1 - Are there any significant differences between Validated Observations after Practical teaching and after two weeks with Repetition using the web course (A - C)?

RQ2 - Are there any significant differences between Validated Observations after Verbal repetition (one week from Practical teaching) and after Repetition using the web course (two weeks after Practical teaching) (B - C)?

RQ3 - Are there any significant differences between Validated Observations with No repetition (in the seventh week) and original Practical teaching (D - A)?

RQ4 - Are there any significant differences between Validated Observations after No repetition (in the seventh week) and after final Repetition using the web course (in the thirteenth week) (D - F)?

RQ5 - Are there any significant differences between Validated Observations after one

$\mid$\begin{tabular}{l} 
PROBLEMS \\
OF EDUCATION \\
IN THE 21 $1^{\text {st }}$ CENTURY \\
Vol. 77, No. 4, 2019 \\
\hline 465
\end{tabular} 
Petr BENDA, Jan PAVLÍK, Jan MASNER. Practical education of adults with intellectual disabilities using a web course

PROBLEMS

OF EDUCATION

IN THE $21^{\text {st }}$ CENTURY

Vol. 77, No. 4,2019

466

month and one week with verbal repetition and after two months with repetition using only the web course $(\mathrm{E}-\mathrm{F})$ ?

RQ6 - Are there any significant differences between Validated Observations between both Repetitions using the web course $(\mathrm{C}-\mathrm{F})$ ?

\section{Research Methodology}

\section{General Background}

A group of ten participants with intellectual disabilities was educated to acquire basic skills in horticulture. In May 2017, within one week of their studies (first week of the research), they were able to learn four basic skills. Planting seeds in pots, Planting seedlings in pots, Watering using a watering can, Weeding the flowerpot. Teaching was realized through practical demonstrations at the workplace in the production garden. These demonstrations were also recorded in the form of a video for future use in the web course.

\section{Sample}

Research participants were people with various levels of intellectual disability (formerly called mental retardation). The specific level of intellectual disability of each participant is described in Table 1. For a more detailed understanding of various intellectual disability levels, it is appropriate to use a description published by Gluck (2014):

- People with mild intellectual disability are slower than typical in all developmental areas, they have no unusual physical characteristics, they are able to learn practical life skills and blend in socially;

- People with moderate intellectual disability have noticeable developmental delays (i.e. speech, motor skills), they may have some physical signs of impairment (i.e. thick tongue), they are able to communicate in basic, simple ways and complete self-care activities;

- People with severe intellectual disability have considerable delays in development, they are able to understand speech, but they have little ability to communicate, they are able to learn daily routines and tasks and may learn very simple self-care;

- People with profound intellectual disability have significant developmental delays in all areas, they require an attendant to help in self-care activities, they may respond to physical and social activities, they are unable to live independently.

During the research, all participants were not employed and previously worked only in sheltered workshops. The research was regularly attended by ten participants described in Table 1 . 
Table 1. List of participants.

\begin{tabular}{lllll} 
& Age & $\begin{array}{l}\text { Level of intellectual } \\
\text { disability }\end{array}$ & Kind of disability & Associated disability \\
\hline Participant A & 60 & Mild & Perinatal hypoxia-ischemia & Moderate visual impairment \\
\hline Participant B & 47 & Moderate & Perinatal hypoxia-ischemia & - \\
\hline Participant C & 48 & Moderate & Down Syndrome & - \\
\hline Participant D & 52 & Mild & Down Syndrome & - \\
\hline Participant E & 62 & Mild & Perinatal hypoxia-ischemia & - \\
\hline Participant F & 53 & Moderate & Down Syndrome & - \\
\hline Participant G & 46 & Mild & Down Syndrome & Hearing impairment \\
\hline Participant H & 41 & Mild & Down Syndrome & Hearing impairment \\
\hline Participant I & 37 & Moderate to severe & Perinatal hypoxia-ischemia & Lower extremity motor \\
\hline Participant J & 49 & Severe to profound & Perinatal hypoxia-ischemia & Motor disability \\
\hline
\end{tabular}

Ethics

Data of all participants were anonymized and summarized in a table so that the work results could also be evaluated on specific types and degrees of disability. Level of intellectual disability of each participant was taken from medical records with the permission of doctors by caregivers to serve as complex aggregate data adapted according to the amount and type of intervention needed (Gluck, 2014) and classification of American Psychiatric Association (1994), which categorizes mental retardation (intellectual disability) into four main categories: mild (IQ score of 50-55 to approximately 70), moderate (IQ score of 30-35 to 50-55), severe (IQ score of 20-25 to 35-40), and profound (IQ score of less than 20-25). Individual levels are based on the result obtained by standardized IQ cognitive tests.

No concrete data of any participant were used. The information showed in Table 1 was not known to the researchers until the end of all observations. Until the end of the research process, the results of the observations were assigned to the real first names of participants. All research was done in the university production garden therefore, it was a part of university legally binding contracts and agreements.

\section{Instrument and Procedures}

As it was mentioned before, the evaluation of each participant activity was performed gradually in six steps by Validated Observations (Figure 1). Observational research and more concretely Participant observations were used. The first observation was made at the end of the first week after the original practical teaching. Further Validated observations were made at different weekly intervals. After each step (Validated Observation), all participants were tested to verify their obtained skills. Individual activities were divided into sub-tasks. Each sub-task was assessed on an interval scale of $0-4$ points. The better the participant has mastered the sub-task, the more points were awarded ( 0 - inadequate, 4 - excellent). Tasks were evaluated in terms of quality, speed, and precision of execution. The sum of points obtained in various tasks reflects the level of activity for each participant. The training and testing of participants were conducted by an expert in the field of horticulture. Data collection for Validated Observations 
Petr BENDA, Jan PAVLÍK, Jan MASNER. Practical education of adults with intellectual disabilities using a web course

PROBLEMS

OF EDUCATION

IN THE $21^{\text {st }}$ CENTURY

Vol. 77, No. 4,2019

was realized through Systematic observation (Fraenkel, Wallen, \& Hyun, 2015), also known as Structured observation method.

For example, during the sub-task "soil gathering" each participant was evaluated based on the way they gathered soil into the pot in terms of conducted education - whether they pick it up directly using the flowerpot (correct procedure) or if they fill the pot up gradually by hand, etc. For the sub-task "Seed placement" it was evaluated whether the participant placed the seed at the center of the pot, if the seed is placed to a sufficient depth and so on. All tasks and subtasks were formulated and verified in a similar manner. In order to maintain the same scoring system across tasks, each task was divided into exactly four sub-tasks.

Table 2. Planting seeds in pots task results (consists precisely of four sub-tasks).

\begin{tabular}{lcccccc}
\hline $\begin{array}{l}\text { Planting seeds in pots after } \\
\text { Practical teaching }\end{array}$ & Soil gathering & Pot preparation & $\begin{array}{c}\text { Seed } \\
\text { placement }\end{array}$ & Soil flattening & Total & Average \\
\hline Participant B & 3 & 2 & 3 & 4 & 12 & 3 \\
\hline Participant B & 3 & 3 & 4 & 3 & 13 & 3.25 \\
\hline Participant C & 3 & 2 & 3 & 3 & 11 & 2.75 \\
\hline Participant D & 3 & 3 & 4 & 4 & 14 & 3.5 \\
\hline Participant E & 3 & 3 & 3 & 3 & 12 & 3 \\
\hline Participant F & 1 & 0 & 1 & 1 & 3 & .75 \\
\hline Participant G & 2 & 3 & 3 & 4 & 12 & 3 \\
\hline Participant H & 3 & 3 & 2 & 2 & 10 & 2.5 \\
\hline Participant I & 3 & 3 & 2 & 3 & 11 & 2.75 \\
\hline Participant J & 1 & 1 & 0 & 0 & 2 & .5 \\
\hline
\end{tabular}

The total score of each participant within each task is used for the summation of all task per each Validated Observation. For example, Participant 1 received the following total score after the first week of practical teaching:

- Planting seeds in pots - 12;

- Planting seedlings in pots - 14;

- Watering using a watering can - 3;

- Weeding the flowerpot -12 .

So, the total score of Participant 1 after the first Validated Observation "Practical teaching" was 41 . The same method was used for all participants and all Validated Observations. The data obtained in this manner was used to compare the overall results of all six Validated Observations.

Intervals between observations were selected with regard to the problems of people with intellectual disabilities and their memory. Long-term memory functioning in individuals with mental retardation has been extensively investigated. Studies performed by Ellis (1970) and Swanson (1989) in which mentally retarded patients have been compared with chronological age-matched subjects have consistently documented impaired memory performance in the mentally retarded groups.

The first Validated Observation was carried out at the end of the basic practical teaching week. The second observation was prepared one week later in the same concept as all participants were used to from the work in sheltered workshops. In these workshops, they were working supervised by caregivers with frequent verbal repetition and repetitive demonstration. During 
the second step, the research continued in the same way but using only verbal repetition with no real demonstrations. Two weeks after verbal repetition the next repetition of already learned activities using a web course was conducted. Use of the web course is described below.

After the Validated Observation using the web course activities with participants were suspended and participants did not visit the working environment in the garden. Four weeks later participants were taken into the garden again and exposed to the performance of tasks without any repetition and help. After the next two weeks, the situation was repeated but with verbal repetition of all sub-tasks. The last Validated Observation used a web course again. All observations were conducted under the same conditions and in the same working environment.

\section{Web Course Design and Interface}

Web technologies were used because of their platform independence and ease of use. The simple HTML web page may be used on almost any device (Connor, 2012). More important than the technology for content development itself is the way participants interact with that technology, based on each individual background of users and their previous experience (Šimek, Vaněk, \& Pavlík, 2015). According to the conducted research, (e.g., Benda \& Šmejkalová, 2015; Denaes, 2012; Huguenin, 2000; van de Ven \& de Haan, 2003) people with intellectual disabilities prefer to use the touch screen as a very convenient tool to control the computer and a web page.

Team of Alonso-Virgos, Pascual Espada, Rodríguez Baena and Crespo R. G. (2018) have presented research with the important result that persons with Down syndrome may have motor problems using the mouse. $70 \%$ of those tested individuals have these problems, which means that their response time was slow. Although the use of computers cannot completely overcome the difficulties and limited functions associated with a mental disability, research has proved that this device improves performance and reduces memory usage, as demonstrated by other studies (Andrich, Gower, \& Vincenti, 2012; Brown et al., 2011; Foshay \& Ludlow, 2005). Using mobile technologies and multimedia increases student interest and helps them learn while they are fun. In the case of students with disabilities, training exercises must be individualized to meet their special educational needs (Fernández-López, Rodríguez-Fórtiz, Rodríguez-Almendros, \& Martínez-Segura, 2013).

The web course, which was developed and used for the research, was formed by simple buttons with a short text description and a pictogram representing the given activity. Once the participant clicked on the button, short video material, which was acquired earlier in the education of participants and subsequently adapted to the needs of the web course, or narrated animation was displayed, showing any given activity. This participant was allowed to simply repeat the operation and then perform it without the assistance of a caregiver.

Research participants use pictograms in everyday life, e.g. for determining the types and intensity of pain. This use of pictograms is also mentioned by de Knegt, et al. (2016) or Mirenda (2003). Other studies confirm that the use of pictograms for the education of people with mental disabilities is appropriate, reducing their uncertainty, improving their ability to read, facilitating communication and allowing them to make decisions independently (Falck, 2001; Guerrier, Kolski, \& Poirier, 2013; Rodríguez-Fórtiz et al., 2009; Smithers \& Puffett, 1996). This type of navigation should also be used with regard to other studies (Caria, Paternò, Santoro, \& Semucci, 2018; Pereira \& Archambault, 2016; Rodríguez, Pérez, Cueva, \& Torres, 2017) identifying potential problems using the classic web interface. Alonso-Virgos et al. (2018) have confirmed in their research that people with Down syndrome may have troubles for understanding the meaning of icons, also common icons and may have troubles for understanding a complex text.

In the research, there were always used the same pictograms to show specific activities. These pictograms were used not only in the web application, but they were also stationed directly

PROBLEMS
OF EDUCATION
IN THE 21 $1^{\text {st }}$ CENTURY
Vol. 77, No. 4, 2019 
PROBLEMS

OF EDUCATION

IN THE $21^{\text {st }}$ CENTURY

Vol. 77, No. 4, 2019

470

at the areas for performing activities, they were part of video-materials and animations and they were placed on certain tools. These pictograms have become an integral but unobtrusive part of the everyday working life of participants.

Like it was mentioned already, the research was situated in the University production garden. The garden is quite large therefore it was necessary to enable mobility of equipment used. Mobile devices (e.g. tablets, smartphones) are shown to be effective tools for empowering people with intellectual disability to live and work with greater independence (e.g., Kagohara et al., 2010; Mechling, Gast, \& Seid, 2010; Wade \& Troy, 2001). As it is described above the touch screen is the most suitable technology for controlling the web page. Benda and Šmejkalová (2015), add that for the persons with intellectual disabilities it is also appropriate to use touch screen by one hand only without a need using the other hand to hold equipment and for the simple control of an application it is suitable not to use or create applications that require multitouch, zooming or scrolling. It also implies that the application should display all the content at once which then adapts to the device. Several studies, e.g. Brown et al. (2011) or Kwon and Lee (2016), also demonstrate that people with intellectual disabilities are able to use more complex interfaces.

\section{Data Analysis}

T-Tests were used to compare means where Validated Observations data was assumed to be normally distributed. Kolmogorov-Smirnov test indicated that all Validated Observations in Table 3 follow a normal distribution $(p<.05)$. In the case of small data sets, a test of significance for normality may lack the power to detect the deviation of the variable from normality. Therefore, non-parametric statistical tests were used despite the fact that prior research has shown that data does not violate the normality assumption on which the t-Test relies (e.g., Rock, Webb, McNaughton, \& Bell, 1987; Siegel \& Castellan, 1988). For that reason, the equivalent non-parametric Wilcoxon signed-rank test for statistical hypothesis testing was used.

Table 3. Descriptive statistics and Kolmogorov-Smirnov (K-S) test for normality result.

\begin{tabular}{lccccccc}
\hline Validated Observations & $\boldsymbol{n}$ & $\boldsymbol{M}$ & $\boldsymbol{M d n}$ & $\boldsymbol{S D}$ & $\boldsymbol{M i n}$ & Max & K-S test \\
\hline A - Practical teaching & 10 & 35.3 & 39.5 & 13.65 & 7 & 47 & .196 \\
\hline B - Verbal repetition & 10 & 31.9 & 36.0 & 16.24 & 3 & 51 & .112 \\
\hline C - Repetition using the web course & 10 & 33.2 & 36.5 & 15.73 & 0 & 49 & .158 \\
\hline D - No repetition & 10 & 19.5 & 24.5 & 11.17 & 0 & 33 & .157 \\
\hline E - Verbal repetition & 10 & 27.2 & 32.5 & 12.08 & 3 & 39 & .164 \\
\hline F - Repetition using the web course & 10 & 34.0 & 40.5 & 14.67 & 6 & 48 & .170 \\
\hline
\end{tabular}

\section{Research Results}

From the values contained in Table 4, it is possible to determine that the application of Parametric and Non-parametric tests leads to the same results. 
Table 4. $t$-test and Wilcoxon's signed-rank test effect sizes ( $r$ ) results.

\begin{tabular}{|c|c|c|c|c|c|c|c|c|c|c|}
\hline \multirow[b]{2}{*}{$\begin{array}{l}\text { Research } \\
\text { question }\end{array}$} & \multicolumn{4}{|c|}{$t$-test } & \multicolumn{6}{|c|}{ Wilcoxon's signed-rank test } \\
\hline & $\begin{array}{l}\text { Observations } \\
\text { comparison }\end{array}$ & $t$-value & $p$-value & $\begin{array}{l}\text { Result } \\
(p \leq .05)\end{array}$ & $n$ & W-value & Z-value & $p$-value & $\begin{array}{l}\text { Result } \\
(p \leq .05)\end{array}$ & $r$ \\
\hline RQ1 & $A-C$ & 2.2150 & .0540 & no dif. & 10 & 8 & -1.7838 & .0751 & no dif. & .40 \\
\hline RQ2 & $\mathrm{B}-\mathrm{C}$ & 1.3291 & .2165 & no dif. & 10 & 14.5 & -1.3251 & .1833 & no dif. & .30 \\
\hline RQ3 & D-A & 9.0952 & - & dif. & 10 & 0 & -2.8031 & .0051 & dif. & .63 \\
\hline RQ4 & D-F & 6.3017 & .0002 & dif. & 10 & 0 & -2.8031 & .0051 & dif. & .63 \\
\hline RQ5 & $\mathrm{E}-\mathrm{F}$ & 4.3732 & .0018 & dif. & 10 & 0 & -2.8031 & .0051 & dif. & .63 \\
\hline RQ6 & C-F & .5794 & .5766 & no dif. & 8 & 16 & -.2801 & - & no dif. & .06 \\
\hline
\end{tabular}

The results of the tests confirmed that there are no statistically significant differences in research questions RQ1, RQ2 and RQ6 at $p \leq .05$. It means that during the first part of the conducted research, there was no statistically significant difference between results of Validated Observations which were measured after Practical teaching and results after Repetition using the web course, which was performed 3 weeks after original Practical teaching (A - C). No statistical evidence also suggested that Verbal repetition and Repetition using the web course differ (B - C). An important result is that there was no statistically significant difference between both Repetitions using the web course. Accordingly, the results of all participants during observations after Repetition using the web course in the third week and in the thirteenth week were not significantly different $(\mathrm{C}-\mathrm{F})$.

On the contrary, there were statistically significant differences in Research questions RQ3, RQ4 and RQ5 at $p \leq .05$. When the participants had to perform activities without any repetition, their results were significantly different from those measured after the Verbal repetition or the Repetition using the web course (D - A and D - F). Interesting results were obtained by comparing the Verbal repetition in the ninth week with Repetition using the web course in the thirteenth week (E - F). Despite the lack of any contact with participants for four weeks, there could be a statistically significant difference observed, so based on the measured results, it is possible to declare the Repetition using the web course was a better method than the simple Verbal repetition only.

The effect sizes for the Wilcoxon's signed-rank tests were also computed using the formula given in Pallant (2007) and Rosenthal (1991, p. 19; 1994). The suggestion of Cohen (1992) that effect sizes of .20 are small, .50 are medium, and .80 are large allows the researcher to compare the experiment's effect size results in known scales.

The effect size for Research questions RQ1, RQ3, RQ4, and RQ5 acquired values from .40 to .63 , which can be considered as medium effects. Research question RQ2 with $r=.3$ can be marked as small to medium effect size. The last Research question RQ6 has small effect size with $r=.06$ (Cohen, 1988; Rosnow, \& Rosenthal, 1996).

The results proved that participants achieved the best results after the original practical teaching and after the repetition using the web course when they immediately applied the information obtained. The visual presentation of information in the web course enabled users to obtain a comprehensive overview of individual activities and therefore they were able to better remember the obtained knowledge and use it in practice. The reason was that most educational materials within the course were in the form of videos that describe individual tasks very precisely and step by step. The research also confirmed that the visual representation of knowledge and use of pictograms was a suitable form of teaching material for people with intellectual disability especially if these pictograms were also used further in their real environment. 
PROBLEMS

OF EDUCATION

IN THE $21^{\text {st }}$ CENTURY

Vol. 77, No. 4, 2019

472

During the research, it was possible to observe that participants had become accustomed to using the web course. Within the last observation, eight out of ten participants were able to navigate and use proper material in the developed web course for the requested task independently. Observation results and thus the quality of the performed work was the second best after the practical teaching. Based on the findings, Verbal repetition alone appears to be insufficient.

Two weeks after the research the participants also had to work in a common garden of the sheltered house where they lived. This area is considerably different from the university garden where the whole research took place. Not all the participants attended this activity thus it was not possible to prepare observation adequately, therefore there were no observed data for this period. There was just the computer with touchscreen prepared, the same one as was used for all observations, and the same pictograms, which were used during all the research, were placed to the appropriate locations. Most of the participants were able to find a location for the required activity, identify the pictogram of the required activity, navigate the web course on a computer nearby to find proper content and apply the refreshed knowledge into practice. Due to differences in the working environment, the results and the quality of work were not as good as in the last observation in university garden, but despite the change of environment, the participants were able to carry out the necessary actions independently and only with minor help from a caregiver.

Various difficulties in the utilization of the web course which were not present in practical teaching were observed too. The participants mostly used the course for reduction of their inherent uncertainty. When the participants were left without greater supervision, some of them tried to see the required material again after each completed activity, for example after planting of seeds in every pot. In the real working deployment, this would lead to considerable time losses. So, despite the evidence of the suitability of the web course, the presence of a caregiver with knowledge of the environment and given activities is a necessity.

Figure 2 shown below demonstrates the form of the web course used in the research. Specifically, it contains a Watering sub-page with watering black and white pictogram, embedded video material with the example of watering procedure and colored pictogram which leads the user to the home page after a click.

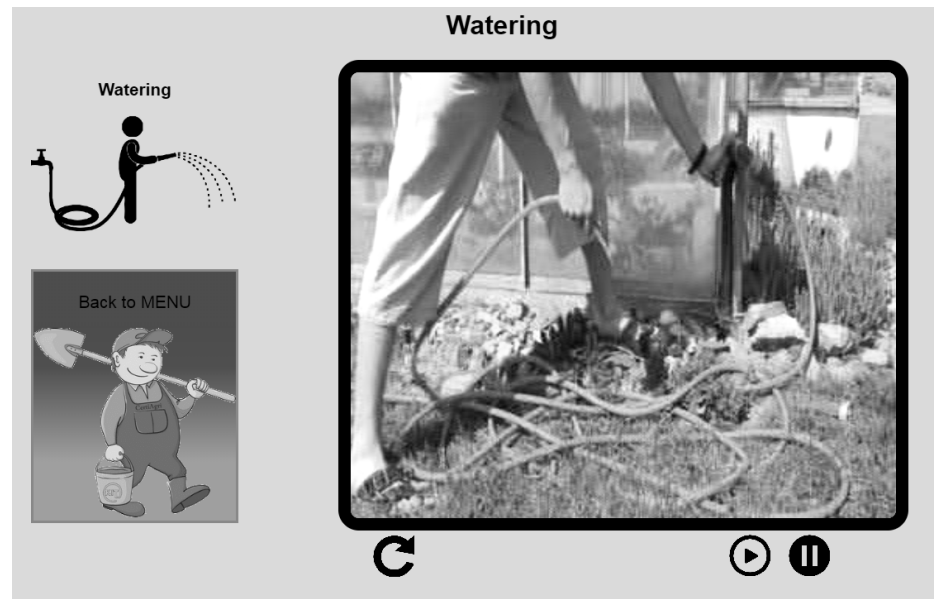

Figure 2. Web course screenshot with a Watering demonstration video. 


\section{Discussion}

The research has analyzed whether a web course could be an appropriate tool for people with intellectual disabilities. A partial goal was to enable people with intellectual disabilities to be educated in the field of horticulture by repeating individual activities through a web course. For more significant statistical verification of the web course suitability, it would be useful to conduct research with a greater number of participants. Observations could be performed randomly over a longer time period and preferably inside a real working environment during a real or simulated workday. But for the first design of such research and also communication difficulties and leadership of the participants with intellectual disabilities a relatively low number of participants, in other similar studies, has been applied (Alonso-Virgos et al., 2018; Caria et al., 2018; Pereira \& Archambault, 2016; Rocha, Paredes, Barroso, \& Bessa, 2016).

In case of the intended use of the web course that is online, it is also necessary to consider many other associated risks. In the case of this research, the offline course in a web browser was used and the user was not allowed to turn this application off or change the application without a keyboard, knowing the proper combination of keys. Due to other studies (e.g. Benda \& Šmejkalová, 2015; Denaes, 2012; Huguenin, 2000; van de Ven \& de Haan, 2003), the participants were able to use just the touch screen and no other device and the computer was not connected to the Internet. If a user with an intellectual disability was allowed to use the computer freely and for example to turn off the web course, it often led the user getting lost or confused and subsequently stressed by the emerged situation.

It is also appropriate to consider the actual content of the web course. In the case of the research, it consisted of short ( 30 seconds at maximum) video materials or narrated animation traceable by the use of pictograms. Video-materials were taken during real meetings and original teaching of participants. All research participants were already accustomed to the use of pictograms in their daily life, so the content they were most familiar with was used. But there might be better systems for easy navigation, understanding, and connection with real environment and practice. An example of such principle or technology might be Augmentative and alternative communication which is most commonly used to designate mechanical and electronic systems that provide communicative access to people with cerebral palsy and other physical disabilities (Smithers \& Puffett, 1996). Part of this type of communication is also pictorial representation systems. These include Bliss and Rebus system and Picture Communication Symbols also (Foreman, 1998). But these systems cannot substitute ordinary communication and human interaction (Parsons \& Wills, 2014). For example, Blissymbols or Blissymbolics could be an appropriate extension of the developed web course in case all the participants were familiar with this system and used it in daily life. Due to other studies (Alonso-Virgos et al., 2018; de Knegt et al., 2016; Guerrier et al., 2013) and also as a result of observations in presented research, people with intellectual disabilities may have troubles for understanding the meaning of common icons.

Further expansion of this research should be focused on an extension of the use of created web interface to other activities that people with intellectual disabilities do as their work activities. The same solution can subsequently be used to repeat the more complex activities that these people perform during normal day mode without the need of being supported by caregivers in such a high level of daily care.

\section{Conclusions}

The presented research examined whether a web course could be effective educational technology for people with intellectual disabilities focusing on repetition of knowledge, which students (participants) have learned earlier during the practical teaching. All teaching and 
Petr BENDA, Jan PAVLÍK, Jan MASNER. Practical education of adults with intellectual disabilities using a web course

PROBLEMS

OF EDUCATION

IN THE $21^{\text {st }}$ CENTURY

Vol. 77, No. 4, 2019

474

observations have been carried out in a university production garden by professional gardeners. In particular, the web interface was used with regard to its platform and operating system independence, easy portability, and editability.

Based on a selected number of research participants it has been possible to conclude that the results have been promising. The results have demonstrated that a developed web course, the content of which consists of short narrated video or animation, combined with the use of pictograms for confident navigation, can be used by people with intellectual disabilities. Conducted observations have confirmed that the working results of the participants after using a developed web course have not been significantly different from the practical training and the results have been better than a classical verbal repetition by caregivers. At the same time, in addition to practical teaching, this has been the second best-rated approach of repeating knowledge. Using a web course, the participants have achieved similar work results as they have done in practical teaching. On the contrary verbal repetition of knowledge by caregivers has appeared to be insufficient. In addition, this web course could be autonomously exploited by its users at work whenever they wanted, at their own pace and without the need of being supported by caregivers all the time. Utilization of the web course may lead to more efficient employment of people with intellectual disabilities, their greater autonomy in the working process, lower demands on caregivers and thus overall better work performance. The research has also confirmed that the visual representation of knowledge and use of pictograms for navigation have been a suitable form of teaching material for people with intellectual disabilities especially if these types of pictograms have been also used further in their real environment. During the last month of observations, eight participants have been able to navigate and use proper material in the developed web course for the requested task independently, so they became accustomed to using the web course.

The added value of this research is the opportunity to work for two research participants with Down syndrome as real auxiliary workers in horticulture, more specifically in the garden of a sheltered workshop.

\section{Acknowledgements}

The research was realized with the support of the Internal Grant Agency (IGA) of FEM CULS in Prague, no. 2019B0009 - "Life Sciences 4.0 ".

\section{References}

Adam, T., \& Tatnall, A. (2008). Using ICT to improve the education of students with learning disabilities. Learning to Live in the Knowledge Society, 281, 63-70. doi: 10.1007/978-0-387-09729-9_8.

Alonso-Virgos, L., Pascual Espada, J., Rodríguez Baena, L., \& Crespo, R. G. (2018). Design specific user interfaces for people with Down syndrome using suitable WCAG 2.0 guidelines. Journal of Ambient Intelligence and Humanized Computing, 9(5), 1359-1374. doi: 10.1007/s12652-0170539-8.

American Psychiatric Association. (1994). Diagnostic and statistical manual of mental disorders (4th Ed). Washington, DC: American Psychiatric Association.

Andrich, R., Gower, V., \& Vincenti, S. (2012). Information needs related to ICT-Based assistive solutions. In K. Miesenberger, A. Karshmer, P. Penaz, \& W. Zagler (Eds.), Computers helping people with special needs. 13th International Conference, ICCHP 2012 (pp. 207-214). Lecture Notes in Computer Science, vol 7382. Springer, Berlin, Heidelberg. doi: 10.1007/978-3-642-31522-0_31.

Benda, P., \& Šmejkalová, M. (2015). Web interface for education of mentally disabled persons for work in horticulture. Agris On-Line Papers in Economics and Informatics, 7(1), 13-19.

Brown, D. J., McHugh, D., Standen, P., Evett, L., Shopland, N., \& Battersby, S. (2011). Designing location-based learning experiences for people with intellectual disabilities and additional sensory impairments. Computers and Education, 56(1), 11-20. doi: 10.1016/j.compedu.2010.04.014. 
Caria, S., Paternò, F., Santoro, C., \& Semucci, V. (2018). The design of web games for helping young High-Functioning Autistics in learning how to manage money. Mobile Networks and Applications, 23(6), 1735-1748. doi: 10.1007/s11036-018-1069-0.

Clarke, A., \& Clarke, A. (2003). Human resilience: A fifty year quest. London: J. Kingsley Publishers.

Cohen, J. (1988). Statistical power analysis for the behavioral sciences (2nd Ed.). Hove: Lawrence Earlbaum Associates.

Cohen, J. (1992). A power primer. Psychological Bulletin, 112(1), 155-159.

Connor, J. O. (2012). Pro HTML5 Accessibility: Building an inclusive web (1st ed.). New York: Distributed to the book trade worldwide by Springer Science+Business Media. doi: 10.1007/978-1-43024195-9.

de Knegt, N.C., Schuengel, C., Lobbezoo, F., Visscher, C.M., Evenhuis, H.M., Boel, J.A. \& Scherder, E.J.A. (2016). Comprehension of pictograms for pain quality and pain affect in adults with Down syndrome. Journal of Intellectual \& Developmental Disability, 41(3), 222-232. doi: $10.3109 / 13668250.2016 .1176129$.

Denaes, C. (2012) Analogical matrices in young children and students with intellectual disability: Reasoning by analogy or reasoning by association. Journal of Applied Research in Intellectual Disabilities, 25(3), 271-281. doi: 10.1111/j.1468-3148.2011.00665.x.

Eggleton, I., Robertson, S., Ryan, J., \& Kober, R. (1999). The impact of employment on the quality of life of people with an intellectual disability. Journal of Vocational Rehabilitation, 13(2), 95-107.

Ellis, N. R. (1970). Memory processes in Retardates and Normals. In N. R. Ellis (Editor), International Review on Mental Retardation, 1970(4), 1-32. New York: Academic Press. doi: 10.1016/S00747750(08)60021-X.

Evans, S. (2007). Disability, skills and work: Raising our ambitions [Online]. Retrieved 2019, May 28, from http://www.smf.co.uk/wp-content/uploads/2007/06/Publication-Disability-Skills-andWork-Raising-our-ambitions.pdf.

Falck, K. (2001). The practical application of pictogram (1st ed.). Umeå: Swedish Institute for Special Needs Education.

Farris, B., \& Stancliffe, R. J. (2001). The co-worker training model: Outcomes of an open employment pilot project. Journal of Intellectual \& Developmental Disability 26(1), 145-161. doi: 10.1080/13668250020054459.

Fernández-López, Á., Rodríguez-Fórtiz, M. J., Rodríguez-Almendros, M. L., \& Martínez-Segura, M. J. (2013). Mobile learning technology based on iOS devices to support students with special education needs. Computers \& Education, 61(1), 77-90. doi: 10.1016/j.compedu.2012.09.014.

Foreman, P., \& Crews, G. (1998). Using augmentative communication with infants and young children with Down syndrome. Down Syndrome Research and Practice, 5(1), 16-25.

Forrester-Jones, R., Jones, S., Heason, S., \& Di Terlizzi, M. (2004). Supported employment: A route to social networks. Journal of Applied Research in Intellectual Disabilities 17, 199-208. doi: 10.1111/j.1468-3148.2004.00199.x.

Foshay J. D., \& Ludlow B. L. (2005). Implementing computer-mediated supports and assistive technology. In M.L. Wehmeyer\& M. Agran (Eds.), Mental retardation and intellectual disabilities: Teaching students using innovative and research-based strategies (pp. 101-126). Boston, MA: Pearson Custom Publishing, 2005.

Fraenkel, J. R., Wallen, N., \& Hyun, H. (2015). How to design and evaluate research in education (9th Ed.). New York: McGraw-Hill Education.

Guerrier, Y., Kolski, C., \& Poirier, F. (2013). Towards a communication system for people with Athetoid cerebral palsy. Lecture Notes In Computer Science, 8120, 681-688. doi: 10.1007/978-3-64240498-6_61.

Gluck, S. (2014, May 21). Mild, moderate, severe intellectual disability differences [Blog post]. Retrieved 2019, June 20, from https://www.healthyplace.com/neurodevelopmental-disorders/intellectualdisability/mild-moderate-severe-intellectual-disability-differences.

Huguenin, N.H. (2000). Reducing overselective attention to compound visual cues with extended training in adolescents with severe mental retardation. Research in Developmental Disabilities, 21(2), 93113. doi: 10.1016/S0891-4222(00)00027-5.

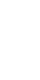


Petr BENDA, Jan PAVLÍK, Jan MASNER. Practical education of adults with intellectual disabilities using a web course

PROBLEMS

OF EDUCATION

IN THE $21^{\text {st }}$ CENTURY Vol. 77, No. 4,2019

476

Kagohara, D. M., van der Meer, L., Achmadi, D., Green, V. A., O’Reilly, M. F., Mulloy, A., Lancioni G. E., Lang R., \& Sigafoos J. (2010). Behavioral intervention promotes successful use of an iPodbased communication device by an adolescent with Autism. Clinical Case Studies, 9(5), 328-338. doi: $10.1177 / 1534650110379633$.

Kober, R., \& Eggleton, I. R. C. (2005). The effect of different types of employment on quality of life. Journal of Intellectual Disability Research, 49, 756-760. doi: 10.1111/j.1365-2788.2005.00746.x.

Kraemer, B. R., McIntyre, L. L., Blacher, J., \& Taylor, S. J. (2003). Quality of life for young adults with mental retardation during transition. Mental Retardation, 41(4), 250-262.

Kregel, J., \& Dean, D.H. (2002). Sheltered vs. supported employment: A direct comparison of longterm earnings outcomes for individuals with cognitive disabilities [Online]. In J. Kregel, D.H. Dean \& P. Wehman (Eds.), Achievements and challenges in employment services for people with disabilities: The longitudinal impact of workplace supports monograph (pp. 63-84). Richmond,VA: Virginia Commonwealth University. Retrieved 2019, March 14, from https:// worksupport.com/documents/shelteredchap3.pdf.

Kwon, J., \& Lee, Y. (2016). Serious games for the job training of persons with developmental disabilities. Computers and Education, 95, 328-339. doi: 10.1016/j.compedu.2016.02.001.

Liberman, R. P., \& Kopelowicz, A. (2002). Teaching persons with severe mental disabilities to be their own case managers. Psychiatric Services, 53(11), 1377-1379. doi: 10.1176/appi.ps.53.11.1377.

Mechling, L. C., Gast, D. L., \& Seid, N. H. (2010). Evaluation of a personal digital assistant as a selfprompting device for increasing multi-step task completion by students with moderate intellectual disabilities. Education and Training in Autism and Developmental Disabilities, 45, 422-439.

Mirenda, P. (2003). Toward functional augmentative and alternative communication for students with autism: Manual signs, graphic symbols, and voice output communication aids. Language, Speech and Hearing Services in Schools, 34(3), 203-216. doi: 10.1044/0161-1461(2003/017).

Murphy, S. T., \& Rogan, P. M. (1995). Closing the shop: Conversion from sheltered to integrated work. Baltimore: Paul H. Brookes Pub.

Pallant, J. (2013). SPSS survival manual: A step by step guide to data analysis using SPSS for Windows. (3rd Ed.). Milton Keynes: Open University Press.

Parsons, C. L., \& Wills, J. (2014). Parental compliance with recommendations to utilize Augmentative communication with their children with Down syndrome. Australian Journal of Human Communication Disorders, 20(2), 1-19. doi: 10.3109/as12.1992.20.issue-2.01.

Pereira, L. S., \& Archambault, D. (2016). Understanding how people with Cerebral palsy interact with the Web 2.0. In Computers Helping People with Special Needs, 239-242. doi: 10.1007/978-3-31941264-1 32 .

Perera, N. T., Wijerathne, I. S. D., Wijesooriya, M. M., Dharmarathne, A. T., \& Weerasinghe, A. R. (2012). ICT based education for students with special educational needs in Sri Lanka. Paper presented at the International Conference on Advances in ICT for emerging regions, ICTer 2012 - Conference proceedings, 156-164. doi: 10.1109/ICTer.2012.6423026.

Pillay, H. (2000). Cognition and recreational computer games: Implications for educational technology. Journal of Research on Computing in Education, 32(1), 32-41.

Quinn, C. N. (1996). Designing an instructional game: Reflections for quest on independence. Journal of Education and Information Technologies, 1(1), 251-269. doi: 10.1007/BF02350662.

Rocha, T., Paredes, H., Barroso, J., \& Bessa, M. (2016). SAMi: An accessible web application solution for video search for people with intellectual disabilities [Online]. In Computers Helping People with Special Needs, 310-316. Cham: Springer International Publishing. doi: 10.1007/978-3-31941267-2 43.

Rock, N. M. S., Webb, J. A., McNaughton, N. J., \& Bell, G. D. (1987). Nonparametric estimation of averages and errors for small data-sets in isotope geoscience: A proposal. Chemical Geology: Isotope Geoscience Section, 66(1), 163-177.

Rodríguez-Fórtiz, M. J., González, J. L., Fernández, A., Entrena, M., Hornos, M. J., Pérez, A., ... Barragán, L. (2009). Sc@ut: developing adapted communicators for special education. Procedia - Social and Behavioral Sciences, 1(1), 1348-1352. doi: 10.1016/j.sbspro.2009.01.238.

Rodríguez, G., Pérez, J., Cueva, S., \& Torres, R. (2017). A framework for improving web accessibility and usability of open course ware sites. Computers \& Education, 109, 197-215. doi: 10.1016/j. compedu.2017.02.013. doi: 10.1016/j.compedu.2017.02.013. 
Rosenthal, R. (1991). Meta-analytic procedures for social research (Rev. ed.). Newbury Park: Sage Publications.

Rosenthal, R. (1994). Parametric measures of effect size. In H. Cooper \& L. V. Hedges (Eds.), The handbook of research synthesis (pp. 231-244). New York: Russell Sage Foundation.

Rosnow, R. L., \& Rosenthal, R. (1996). Computing contrasts, effect sizes, and counter nulls on other people's published data: General procedures for research consumers. Psychological Methods, 1(4), 331-340. doi: 10.1037/1082-989X.1.4.331.

Siegel, S., \& Castellan, N. J. (1988). Nonparametric statistics for the behavioral sciences (2nd ed.). New York: McGrawHill.

Schalock, R., Borthwick-Duffy, S., Bradley, V., Buntinx, W., Coulter, D., Craig, E. (2010). Intellectual disability: Definition, classification, and systems of support (11th ed.). Washington: American Association on Intellectual and Developmental Disabilities.

Smithers, H., \& Puffett, S. (1996). A comparison of augmentative and alternative communication systems used across regions. Proceedings of the 3rd National AGOSCI Conference. Melbourne: Australian Group on Severe Communication Impairment.

Swanson, H.L. (1989). The effects of central processing strategies on learning disabled, mildly retarded, average, and gifted children's elaborative encoding abilities. Journal of Experimental Child Psychology, 47(3), 370-397. doi: 10.1016/0022-0965(89)90020-9.

Šimek, P., Vaněk, J., \& Pavlík, J. (2015). Usability of UX methods in agrarian Sector - Verification. Agris On-Line Papers In Economics And Informatics, 7(3), 49-56.

Turnbull, A., Turnbull, R., Wehmeyer, M. L., \& Shogren, K. A. (2012). Exceptional lives: Special education in today's school (7th ed.). Upper Saddle River, NJ: Merrill.

United Nations Department of Public Information. (2007). Disability and Employment [Factsheet]. Retrieved 2019, May 28, from http://www.un.org/disabilities/documents/toolaction/ employmentfs.pdf.

Van de Ven, J. A., \& de Haan. (2003). Mouse or touch screen. Computers in Psychology, 7, 191-204.

Wade, T. K., \& Troy, J. C. (2001). Mobile phones as a new memory aid: A preliminary investigation using case studies. Brain Injury, 15(4), 305-320. doi: 10.1080/026990501750111256.

Received: April 26, 2019

Accepted: July 25, 2019

\begin{tabular}{|ll|}
\hline Petr Benda & $\begin{array}{l}\text { PhD, Assistant Professor, Czech University of Life Sciences Prague, Department of } \\
\text { Information Technologies, Kamýcká 129, Prague 6, 16521 Czech Republic. } \\
\text { E-mail: bendap@pef.czu.cz } \\
\text { Website: https://kit.pef.czu.cz/en }\end{array}$ \\
\hline Jan Pavlík & $\begin{array}{l}\text { PhD candidate and former Master's Student, Czech University of Life Sciences Prague, } \\
\text { Department of Information Technologies, Kamýcká 129, Prague 6, 16521 Czech } \\
\text { Republic. } \\
\text { E-mail: pavlikjan@pef.czu.cz } \\
\text { Website: https://kit.pef.czu.cz/en }\end{array}$ \\
\hline Jan Masner & $\begin{array}{l}\text { PhD, Postdoctoral Researcher, Czech University of Life Sciences Prague, Department } \\
\text { of Information Technologies, Kamýcká 129, Prague 6, 16521 Czech Republic. } \\
\text { E-mail: masner@pef.czu.cz } \\
\text { Website: https://kit.pef.czu.cz/en }\end{array}$ \\
\hline
\end{tabular}

